\title{
O PROGRAMA PASSAPORTE BIOLÓGICO: CONSIDERAÇÕES SOBRE O GOVERNO DOS ATLETAS
}

\author{
THE BIOLOGICAL PASSPORT PROGRAM: CONSIDERATIONS ON THE \\ GOVERNMENT OF ATHLETES
}
EL PROGRAMA PASAPORTE BIOLOGICO: CONSIDERACIONES SOBRE EL GOBIERNO DE LOS ATLETAS

Viviane Teixeira Silveira*, Luiz Carlos Rigo**

\section{Palavras-chave Doping nos Esportes. Política. Ciência, Tecnologia e Sociedade.}

Resumo: Este artigo tem como objetivo principal fazer uma análise das atuais políticas de doping/antidoping no esporte de rendimento. 0 corpus empírico da pesquisa constituiuse de um conjunto de discursos da Agência Mundial Antidoping (WADA-AMA), do Programa Passaporte Biológico do Atleta e de duas entrevistas com indivíduos que atuam no mainstream esportivo. Amparando-se especialmente no conceito de sociedades de controle, de Gilles Deleuze, (1992), o estudo mostra como as atuais políticas de doping/ antidoping se apropriaram de inovações tecnológicas e de descobertas científicas para construir novas estratégias de controle e de governo dos atletas.
Keywords: Doping in Sports. Athletes.

Politics.

Science, Technology and Society.

Palabras clave Doping en los Deportes.

Política. Ciencia, Tecnología y Sociedad.
Abstract: This article whose main objective was to analyze the current policy proposals doping / anti-doping for sports performance. From an analysis of discourses propagated by the World Anti-Doping Agency (WADA), the Athlete Biological Passport Program and two interviews with individuals active in mainstream sports. Theoretically subsidized by the concepts of control society of Gilles Deleuze (1992), the study indicates how current policies doping/antidoping usurp innovations and scientific discoveries to build new strategies of control and manipulation of athletes.

Resumen: Este artículo tiene como objetivo analizar la corriente política de dopaje/antidopaje en el rendimiento deportivo. El corpus de investigación empírica consistió en una serie de discursos de la Agencia Mundial Antidopaje (WADA-AMA), el Programa Pasaporte Biológico del Atleta y dos entrevistas con las personas que trabajan dentro de la corriente principal de los deportes. Nosotros es el mantenimiento de los conceptos de la sociedad de control, de Gilles Deleuze (1992), el estudio muestra cómo las políticas actuales de dopaje/anti-dopaje apropiarse las innovaciones tecnológicas y los descubrimientos científicos para construir nuevas estrategias de control y el gobierno de los atletas.
*Universidade do Estado de Mato Grosso. Cáceres, MT, Brasil. E-mail: vivianeteixeirasilveira@gmail.com

**Universidade Federal de Pelotas. Pelotas, RS, Brasil.

E-mail: rigoluizcarlos@gmail.com

Recebido em: 29-06-2014

Aprovado em: 16-05-2015

(c) (1) () Licence 


\section{INTRODUÇÃO'}

Denomina-se tecnociência o movimento de inovação e de investimento financeiro "[...] que recobre o planeta de novos artefatos tecnológicos" e assinala "[...] uma interdependência entre as ciências e as técnicas no saber contemporâneo" (ARAÚJO, 1998, p. 11). Essa nova realidade, entendida enquanto processo de transformação da vida em objeto técnico e mercadoria, tem ajudado a forjar um conceito de sujeito virtual e digitalizado (CORRÊA, 2009).

Ao se referir a tecnociência, Donna Haraway (2000) afirma que, principalmente a partir do século XX, passamos a conviver com uma informática da dominação, situada num sistema estatístico probabilístico que formula estratégias de controle em termos de taxas, custos de restrições e graus de liberdade. Para essa autora, essa nova realidade transformou-nos em um híbrido de humano e máquina, um ciborgue. Todavia, Donna Haraway (2000, p. 51) não se atém a lamentar essa situação e nos convoca a tornarmo-nos "ciborgues de oposição."

Ao se referir ao contexto social produzido por essas novas realidades reais/virtuais típicas da era da tecnociência e das subjetividades humanas/maquínicas, que configuram e constituem os sujeitos do século XXI, em um texto intitulado "Post-Scriptum sobre as Sociedades de Controle", o filósofo francês Gilles Deleuze levanta a tese de que, a partir da segunda metade do século XX, a sociedade disciplinar descrita por Michel Foucault estaria cedendo lugar para as "sociedades de controle." Deleuze argumenta que cada vez mais "[...] o controle contínuo substitui o exame." (DELEUZE, 1992b, p. 221).

No esporte moderno especificamente, principalmente no de alto rendimento, as novas realidades oriundas das tecnociências e inseridas nas lógicas das sociedades de controle têm sido utilizadas para aperfeiçoar técnicas de treinamento esportivo, para a melhoria da performance atlética e também para o controle dos atletas por parte da Agência Mundial Antidoping (WADA) agência que promove, coordena e monitora a luta contra o doping no esporte mundial.

Neste artigo, buscaremos, a partir da análise de alguns discursos oficiais da WADA e de um programa de controle permanente dos atletas (Athlete Biological Passport - Programa Passaporte Biológico do Atleta), analisar e refletir sobre as relações entre as tecnologias no esporte e seus desdobramentos nas políticas de doping/antidoping no esporte de rendimento.

O sistema de dados da WADA (ADAMS²) é um exemplo da expansão tecnológica e de seus reflexos diretos na concepção de corpo de atleta que tem se propagado nessas últimas duas décadas. Segundo Corrêa, "[...] os bancos de DNA, ou biobancos, são grandes coleções de material genético (amostras de DNA, células, tecidos, tumores ou órgãos) associados a dados de diversas naturezas (genéticos, médicos, biológicos, familiares, socioambientais)," (CORRÊA, 2009, p. 9), que, conforme veremos, trazem implicações para o esporte contemporâneo.

Para a confecção desse artigo, utilizamos um conjunto de discursos da WADA relativos ao doping/antidoping, mais especificamente discursos relacionados ao Programa Passaporte Biológico. O conceito de discurso foi utilizado conforme o concebe o próprio Deleuze, como práticas discursivas "que são feitas de coisas e de palavras", (DELEUZE, 1988, p. 57).

O entrevistado A é Presidente da Comissão Médica da Organização Desportiva Panamericana - ODEPA, Médico do Comitê Olímpico Internacional (COI) e Membro do Conselho 
de Fundação da Agência Mundial Antidoping. Esse entrevistado nos falou a respeito do processo de fundação da WADA e sobre as amostras e coletas do antidoping. A entrevistada B é Diretora do Escritório Regional Latino-Americano da Agência, localizado atualmente na cidade de Montevidéu, Uruguai. Essa entrevistada acompanhou todo processo de criação da WADA e trabalha coordenando e fiscalizando os países latino-americanos para que cumpram o Código Mundial Antidoping (CODE).

No decorrer do texto, realizamos uma análise e uma reflexão sobre os processos de controle do doping a partir do conceito de "sociedades de controle" de Gilles Deleuze (1992). A apropriação e utilização desse conceito, o qual não foi delineado especificamente para 0 campo esportivo, deu-se de uma forma direta, "do tipo ligação elétrica" (DELEUZE 1992a, p. 16), e possibilitou-nos analisar como as estratégias e os programas de controle transnacionais de doping e antidoping da WADA, objetivam controlar e governar os atletas.

Traçamos nossa reflexão a partir da análise das políticas da WADA que envolvem os testes fora de competição e o Programa Passaporte do Atleta (programa que será apresentado no decorrer do artigo).

\section{DAS TÉCNICAS DE COLETA AOS BIOBANCOS}

O sistema ADAMS 3 , banco de dados responsável por arquivar todas as informações da vida de um atleta, nos ajuda a identificar como essas tecnologias informacionais contribuem para construir novas estratégias de controle vinculadas ao corpo e à vida de atletas. Como exemplo, trazemos a mudança da análise da urina para o sangue.

Os testes de urina foram bem recebidos pela maioria dos atletas e técnicos, principalmente porque não eram vistos como uma agressão aos limites biológicos do corpo, sendo a urina um resíduo (externo ao corpo). Nosso entrevistado A nos contou como o processo de coleta de urina foi tornando-se mais seguro e eficaz com o passar do tempo. O primeiro processo, ocorrido em 1967 ,

Era um processo extremamente rudimentar, nós usávamos frascos que eram vidros de penicilina [...] usávamos tampinhas de borracha, e [...] derretíamos um lacre para fechar a tampa e no lacre a gente usava o anel do príncipe como selo para evitar que o lacre fosse substituído (porque o anel do príncipe com o brasão dele era uma coisa única). (ENTREVISTADO A, 2011)

Os Jogos Olímpicos de Munique em 1972 foram um marco na consolidação das melhores técnicas urinárias, as quais são utilizadas até os dias atuais. Entretanto, os frascos ainda representavam a maior dificuldade para manter válidos o armazenamento e o transporte da amostra. Um kit específico para coleta e armazenamento de urina foi desenvolvido pela empresa Versapak4. Mais sofisticado e profissional, esse kit foi utilizado até os jogos de Barcelona, em 1992. Depois disso, alguns acontecimentos mostraram fragilidades nesse processo: "alguém teve a ideia de levar essa bolsinha numa penitenciária para ver se algum meliante conseguia abri-la, e um dos presos abriu a bolsinha em poucos segundos só com uma tesourinha, abrindo 0 zíper, trocando o vidro e fechando o zíper novamente só com uma tesourinha", (ENTREVISTADO A, 2011).

3 O Sistema de Gestão e Administração Antidoping é uma ferramenta de gerenciamento de banco de dados baseado em web para entrada de dados, armazenamento e compartilhamento projetada para ajudar as partes interessadas e a WADA em suas operações antidoping em conjunto com a legislação de proteção de dados (Athlete Biological Passport Operating Guidelines, 2012, p. 9, tradução nossa).

4 Disponível em: http://versapak-anti-doping.com/. Acesso em: 10 jan.2013. 
Desse modo, desde 1992 até os últimos Jogos de $2008{ }^{5}$, um novo kit vem sendo utilizado. Desenvolvido na Suíça pela empresa Berlinger Special ${ }^{6}$ e aprovado pelo COI/ WADA, o Bereg Kit tem se mostrado extremamente seguro, conforme informações da WADA. Além disso, não só a tecnologia tem melhorado, mas também o próprio local de coleta: "Antes se usava um banheiro comum, hoje se usa um banheiro especial todo espelhado pra tu observares o atleta" (ENTREVISTADO A, 2011).

O médico também ressalta o fato de que a partir do ano 2000, após a criação da WADA, a padronização nas ações facilitou o protocolo porque o controle de doping é exatamente igual em qualquer parte do mundo, ou seja, ele tem um standard internacional que os operadores são obrigados a seguir corretamente.

Entretanto, apesar desse aperfeiçoamento, algumas fragilidades persistiam nos testes de urina. Desse modo, as políticas de controle do doping passaram a utilizar cada vez mais também os exames de sangue, partindo da prerrogativa de que aquilo que não se encontra na urina, se encontra no sangue e vice-versa. Nas provas de natação, por exemplo, os exames antidoping averiguam a utilização de hormônio de crescimento e esteroides anabólicos. Hormônios de crescimento só são encontrados nas amostras de sangue, enquanto que os anabólicos nas de urina.

\section{ATHLETE BIOLOGICAL PASSPORT (ABP) - PASSAPORTE BIOLÓGICO DO ATLETA}

Talvez fazer uma cirurgia, colocar um chip sob a pele. Ou talvez um chaveiro com um tipo de GPS ou algo assim para que possam nos localizar e não tenhamos que ter a responsabilidade de sempre mudar as coisas se nossos horários mudarem. Eles podem nos procurar no mapa e ver onde estamos ${ }^{7}$.

O Programa Passaporte Biológico do Atleta $(A B P)$, um dos mais recentes investimentos da WADA na luta contra o doping, foi proposto no início do ano 2000, mas suas diretrizes e normas somente foram lançadas oficialmente em 2009. Constitui-se de um programa baseado em amostras de sangue coletadas periodicamente, para ter um acompanhamento das variáveis individuais de cada atleta, traçando-Ihes um perfil e acompanhando 0 andamento de sua carreira esportiva. Esse perfil poderá ser utilizado nos exames de doping, para auxiliar nos casos em que houver uma possível manipulação (seja de substâncias exógenas, seja de doping genético) que indique um perfil anormal do atleta. Além disso, os atletas são testados fora de competição. Segundo a WADA, é uma abordagem eficaz porque o atleta pode estar usando substâncias de forma intermitente e com baixa dosagem, método que torna o doping mais difícil de ser detectado por meios convencionais de análise.

Segundo informações extraídas do Guia do Programa ${ }^{8}$, nos últimos anos, os regimes de doping tornaram-se mais planejados e conseguiram tirar proveito das fraquezas dos protocolos tradicionais de controle. Adviria daí a necessidade de um programa mais sofisticado contra o doping.

5 Referimos-nos ao ano de 2008, quando os Jogos Olímpicos foram realizados em Pequim/China, porque foram anteriores à realização de nossas entrevistas. Entretanto, podemos afirmar que em 2012 o mesmo kit (Bereg Kit) foi utilizado.

6 Disponivel em: http://www.berlinger.ch/index.php?id=68\&L=1. Acesso em: 10 jan. 2013.

7 Entrevista da velocista sueca Susanna Kallur para o documentário esportivo "Guerra ao Doping", produzido por Matiné Film \& Television, 2012. 80 Manual com a apresentação do programa, das normas e dos testes está disponível na página da WADA (em inglês e francês) com todas as informações sobre o passaporte hematológico. Os módulos de esteroides e endócrino estão em fase de implementação e seguirão as normas do mesmo manual. O passaporte é o resultado de um agrupamento de todos os dados relevantes de um atleta, os quais podem incluir perfis longitudinais de marcadores, fatores heterogêneos e outras informações relevantes que possam ajudar na avaliação de marcadores. 
O Programa Passaporte do Atleta é baseado na web, interativo, com um formato projetado para que os atletas demonstrem o seu empenho esportivo sem doping ${ }^{9}$. Uma vez inscritos no programa, eles recebem uma identificação com número e senha que permite o acesso ao sistema. Depois, devem atualizar para a WADA seus endereços e horários de treinamento, para testes fora de competição.

Segundo o Guia do Programa (Athlete Biological Passport Operating Guidelines and compilation of required elements - $A B P, 2012^{10}$ ), os atletas-alvo devem ser escolhidos levando em conta, principalmente, aqueles que participam de modalidades esportivas com maior risco de doping sanguíneo (esportes com componente aeróbico e/ou de resistência), atletas que tenham possíveis riscos de estarem dopados, idade do atleta e suas perspectivas de longo prazo, participação em nível de elite, atletas que já tenham sido testados em outros programas, entre outros (Guidelines, 2012).

O Programa tem um banco de dados que armazena e distribui os resultados, tornandose um reservatório de matéria-prima para pesquisas atuais e futuras. Sua forma de constituição e organização, bem como sua finalidade, estão diretamente relacionadas com a aceleração tecnológica que impulsiona o doping no esporte de alto rendimento e revelam uma concepção de humano difundida pelo pensamento tecnocientífico: estatísticas, medidas, amostras.

A WADA argumenta que esse programa serve como uma ferramenta educacional para os atletas, pois contém várias informações de controle de doping, como, por exemplo, a lista de substâncias proibidas e métodos sempre atualizados, bem como regulamentos. Com isso é possível construir uma comunicação entre todos os responsáveis envolvidos no processo, porque os resultados e registros dos atletas com informações de controle de doping ficam mantidos em um banco de dados que pode ser acessado por organismos desportivos nacionais e internacionais, por laboratórios que conduzem os testes e pela WADA. Dessa forma, o intercâmbio de informações e o mútuo reconhecimento dos dados oferece, segundo a WADA, uma melhoria na eficiência da operação das atividades antidopagem (WADA, 2002). "Além disso, os funcionários da WADA têm forte esperança que a base de dados mundial permitirá à WADA e aos funcionários autorizados organizar, harmonizar e ligar programas de exames para compartilhar informações sobre o paradeiro dos atletas para fins de teste." (GUIDELINES $A B P, 2002$, p.9-10, tradução nossa)

Resumidamente, os passos do processo são os seguintes: 1) o atleta é escolhido e identifica-se o que pode ser necessário para o seu passaporte baseado nas informações que já estão disponíveis, tais como histórico de testes já feitos e paradeiro disponível; 2) identificase o momento adequado para a coleta da amostra; 3) as autoridades de coleta de amostras acessam o sistema para saber a localização do atleta; 4) a coleta é efetuada conforme protocolo anexado ao Manual da $A B P($ GUIDELINES ABP); 5) após a coleta e transporte da amostra para um laboratório credenciado, o formulário do passaporte deve ser imediatamente preenchido, para fornecer acesso rápido aos dados relevantes para o atleta, WADA, Federações e Confederações; 6) o laboratório analisa as amostras e divulga os resultados biológicos no sistema $A D A M S$; 7) assim que os novos dados são inseridos no ADAMS, o passaporte do atleta é atualizado; 8) havendo quaisquer modificações nos marcadores ${ }^{11}$ biológicos, um painel de especialistas analisará o processo.

\footnotetext{
9 Disponível em: http://www.wada-ama.org/en/Science-Medicine/Athlete-Biological-Passport. Acesso em: 23 ago.2014. 10 Disponível em: http://www.wada-ama.org/en/Science-Medicine/Athlete-Biological-Passport. Acesso em: 23 ago.2014. 
Segundo o Manual do Programa existem duas maneiras de saber se um atleta usa doping: a primeira é encontrando uma substância dopante nos resultados dos exames, a segunda é ver os sinais ou sintomas de que algo proibido foi utilizado porque "o efeito da droga permanece mais tempo que a própria substância" (GUIDELINES ABP, 2012, p.26, tradução nossa). Como exemplo desses efeitos do uso de doping, nosso Entrevistado (A) disse: "[...] se eu vejo um corpo extremamente forte, uma mulher toda cheia de acne, um rosto muito masculino, poucas curvas, quase sem seio e sem quadril, eu posso assumir que ela tá tomando alguma coisa."

Apesar desses sintomas ou sinais corporais não condenarem o atleta, eles são tomados como indícios, como pistas que levantam suspeitas e são agregadas a outras informações param constituir verdadeiros dossiês de investigação biomédica. Se, até bem pouco tempo atrás, somente se testavam para doping os vencedores de provas e alguns atletas sorteados; atualmente, a situação mudou: a busca é por esse doping inteligente, o qual é baseado, sobretudo, em informação:

[...] informação de atleta que sabe quem se dopa e quem não se dopa, informação de polícia quando há, por exemplo, um tráfico de anabólico, informação de alfândega, informação da Interpol (a Interpol tem um escritório só pra estudar rotas de doping, então ela vê a distribuição no mundo e tenta fazer uma inteligência disso). (ENTREVISTADO A, 2011)

O Programa Passaporte do Atleta segue essa perspectiva de se utilizar da inteligência para o controle de doping, pois com ela é possível traçar um perfil hematológico do atleta e suas variações. Por exemplo, evidências de utilização de eritropoietina só podem ser encontradas num exame sanguíneo e, se um hemograma for feito repetidamente (pelo menos quatro vezes) durante um ano, será possível dizer se um atleta a utiliza ou não, porque o hematócrito dele irá aumentar e os glóbulos vermelhos se tornarão mais numerosos, melhorando o transporte de oxigênio. Nesse processo, mesmo que o doping não seja encontrado diretamente, os sinais da utilização de alguma substância são achados. A partir disso, buscam-se as evidências de uso, e não diretamente de substâncias dopantes. O TAS-CAS (Tribunal Arbitral du Sport - Court of Arbitration for Sport) já aceita esses sinais como prova de doping.

Apesar de até o momento somente duas Federações terem implementado o $A B P$ : a UCI (Union Cycliste Internationale) e a IAAF (Associação Internacional de Federações de Atletismo). A nossa entrevistada observou que:

É algo que está em progresso no sentido da adesão. Eu acredito que vem avançando muito bem, é a ferramenta do futuro, assim a visualizamos. [...] A ideia é que os distintos esportes vão aderir cada vez mais e as distintas organizações antidoping também porque estão vendo os benefícios dos atletas terem seu próprio passaporte biológico. [...] Nem todas as federações tem o programa e por enquanto não é obrigatório. É algo que a WADA recomenda que se faça. (ENTREVISTADA B, 2011, tradução nossa).

Às vésperas dos Jogos Olímpicos de Londres (2012), o corredor português de longa distância Helder Ornelas foi banido por quatro anos pela federação de seu país, tornando-se o primeiro atleta suspenso por doping através do sistema do ABP. Segundo Lamine Diack, presidente da IAAF, a suspensão do atleta de 38 anos, que participou dos 5.000 metros na Olimpíada de Sidney (2000) e da maratona nos Jogos de Pequim (2008), marca um ponto de referência na luta contra o doping. Diack, em comunicado afirmou: 
Aqueles que tentam trapacear dentro da comunidade de atletismo devem ser avisados que o Passaporte Biológico do Atleta não é meramente um conceito, mas um método eficiente que está sendo usado pelo Departamento Antidoping da laaf para identificar, mirar e pegar aqueles que acreditam que doping é a única rota para o sucesso $^{12}$.

As amostras de sangue de Ornelas foram coletadas durante um período de 11 meses a partir de dezembro de 2009 e o sangue foi considerado anormal (perfil hematológico diferente de seus parâmetros habituais) pela primeira vez em maio de 2011, provocando, então, investigações mais profundas. Em especial, novas amostras são testadas em comparação a amostras históricas, para se certificar de que os desvios não aceitáveis na composição bioquímica do atleta possam ter ocorrido. As amostras são agregadas estatisticamente para determinar o limite no qual um corpo puro torna-se juridicamente impuro.

Durante a primeira Conferência Mundial sobre Doping no Desporto (em Lausanne, 1999), alguns representantes de governo sugeriram que a WADA deveria preservar as amostras de urina e de sangue dos atletas pelos 20 anos seguintes, para novas investigações. Assim, se um novo método de teste de droga encontrasse algo nas novas análises, a agência poderia retirar a medalha do atleta, mesmo vários anos após o ocorrido. Dessa forma, podemos observar uma vontade de punir, controlar e regular que extrapola os limites temporais ${ }^{13}$.

A IAAF disponibiliza em seu site um Manual de Medicina, organizado por uma Comissão Médica e Antidoping, como parte de um programa de educação que é realizado em diversos centros de treinamento da Federação. Esse mecanismo tem o objetivo de ajudar os atletas no reforço da sua organização médica e proporcionar aos seus prestadores de cuidados de saúde (médicos e fisioterapeutas) informações atualizadas sobre medicina desportiva e doping, baseadas na legislação antidoping da WADA ${ }^{14}$. Nesse manual está descrito o percurso pelo qual o $\mathrm{COI}$ e a WADA passaram nas políticas antidoping, alguns casos de atletas dopados, os testes durante e fora de competição, a lista de substâncias proibidas, sanções e guias de procedimentos dos testes dentro e fora de competição.

A IAAF foi a primeira Federação a adotar o Passaporte do Atleta. Em 14/12/2010, uma notícia publicada no site da Federação mostra a força que o Programa criado pela WADA vem desempenhando sobre a IAAF. A matéria "Passaporte Biológico do Atleta: uma nova estratégia que é uma grande promessa na luta contra o doping no atletismo" apresenta um novo método de detecção indireta, privilegiando a análise dos marcadores biológicos selecionados, incluindo variações anormais que possam indicar o doping. Esse método é composto por três módulos: hematológico, esteroide e hormonal ${ }^{15}$. Qualquer alteração anormal será transmitida aos peritos médicos e cientistas, os quais compartilham suas opiniões e verificam se a anormalidade pode ser resultado de doping.

12 Passaporte biológico faz primeira vítima de doping no atletismo, 02 maio 2012. Disponível em: http://br.reuters.com/article/ idBRSPE84105420120502. Acesso em: 20 ago. 2012.

13 Um exemplo disso é o caso do ciclista Lance Armstrong, sete vezes vencedor do Tour de France consecutivamente, de 1999 a 2005. Em junho de 2012, a USADA - Agência Antidoping dos EUA - acusou formalmente o atleta de consumo de substâncias ilícitas, baseando-se em amostras sanguíneas de 2009 e 2010. Armstrong foi banido do esporte e teve que devolver suas 7 medalhas, perdendo os títulos já conquistados. Lance Armstrong vai perder seus títulos do Tour de France por doping. 24/08/2012. Disponível em: http://oglobo.globo.com/ blogs/debike/posts/2012/08/24/lance-armstrong-vai-perder-seus-titulos-do-tour-de-france-por-doping-461881.asp. Acesso em: 30 ago.2012.

14 Disponível em: http://www.iaaf.org/medical/manual/index.html, Mais especificamente o capítulo 15. Drogas no Esporte/Controle de Doping. Acesso em: 23 ago. 2014.

15 Detalhes dos procedimentos para coleta, análise e gerenciamento de desempenho estão disponíveis em: http://www.iaaf.org/mm/ Document/Antidoping/Rules\&Regulations/05/26/52/20100521100952_httppostedfile_IAAF_006G_REV1-IAAFBloodTestingProtocol_20413. pdf . Acesso em: 23 ago. 2014. 
No Brasil, a Autoridade Brasileira de Controle de Doping (ABCD) é a entidade com autoridade para a adoção e a implementação das normas antidoping, direção da coleta das amostras, gerenciamento dos resultados dos testes e condução das audiências. No site da Confederação Brasileira de Atletismo (CBAt) há um link para o "Regulamento para controle de doping da $I A A F$ ", traduzido da versão original no inglês, bem como um link denominado "Fora de competição - Para informar sua localização, clique aqui”.

Bastante visível, esse link é parte da política de Passaporte do Atleta e deve ser preenchido pelos atletas que participam do programa. Eles devem manter um cadastro junto a cada entidade, no qual devem informar a cada quatro meses onde podem ser localizados. Se não o fizerem e, ao serem procurados para testes fora de competição, não forem encontrados, podem ser punidos como se houvessem tido um resultado positivo em controle de doping ${ }^{16}$. A IAAF publica em seu site uma lista ${ }^{17}$ com 0 nome dos atletas selecionados para participar do programa, a qual é revista e revisada quando necessário, conforme informações do documento no site. Essa Federação também atenta para a obrigatoriedade dos atletas de manter as agendas atualizadas $^{18}$. Caso 0 atleta não seja encontrado para os testes, ele pode ser considerado culpado ${ }^{19}$.

\section{PROGRAMA PASSAPORTE BIOLÓGICO E SOCIEDADES DE CONTROLE: APROXIMAÇÕES}

Os procedimentos de controle exercidos pelo Programa Passaporte Biológico do Atleta ilustram como as sociedades de controle adentraram o universo do esporte de rendimento. Como assinalou Deleuze, nas sociedades de controle, "[...] não se está mais diante do par massaindivíduo. Os indivíduos tornaram-se 'dividuais', divisíveis, e as massas tornaram-se amostras, dados, mercados ou 'bancos."' Além disso, acrescenta o autor: "[...] a linguagem numérica do controle é feita de cifras, que marcam o acesso à informação, ou a rejeição." (DELEUZE, 1992b, p. 222).

Nesse contexto, o conjunto dos discursos (entrevistas, reportagens, etc.) provenientes da WADA, os quais constituem "[...] regiões de visibilidades e campos de legibilidades, de conteúdos e de expressões" (DELEUZE, 1988, p. 7), indica que a instituição está atenta às inovações oriundas da tecnociência, o que the possibilita acompanhar e controlar as novas estratégias de doping através de novos programas de controle de antidoping, como é o caso, por exemplo, do Passaporte Biológico do Atleta. 0 corpus discursivo analisado mostrou também que no Passaporte Biológico o sangue tornou-se a novidade e o principal componente das estratégias de controle antidoping.

16 Segundo o site da CBAt, "os controles fora de competição são de fundamental importância para o combate ao doping voluntário no Atletismo. A Agência Mundial Antidoping - WADA, assim como a IAAF determinam a adoção de programas para controle de doping fora de competição, com a existência de Grupos de Atletas Registrados para Testes. Para que isto seja possível, eles devem manter um cadastro junto a cada entidade, no qual informam, a cada quatro meses, onde podem ser localizados, ou seja, seus locais de treinamento e competição, quando estão em seus locais de residência ou não. Todo cuidado deve ser tomado pelos atletas para manterem tais cadastros atualizados". Disponivel em: <http://www.cbat.org.br/anad/fora_competicao/default.asp>. Acesso em: 1 out. 2012.

17 Três atletas brasileiros participam, atualmente, do programa da IAAF. São eles: Caio Bonfim (marcha atlética), Jonathan Silva (salto triplo) e Fabiana Murer (salto com vara). Disponível em: http://www.iaaf.org/about-iaaf/documents/anti-doping, atualizada em: 9 jan. 2013. Acesso em: 14 jan. 2013.

18 Rules IAAF, 2012/2013, p.57. Disponível em: http://www.iaaf.org/about-iaaf/documents/anti-doping, atualizada em 24/10/2012. Acesso em: 10 nov. 2012.

19 Rules IAAF, 2012/2013, p.57. Disponível em: http://www.iaaf.org/about-iaaf/documents/anti-doping, atualizada em 24/10/2012. No site também consta uma lista com os nomes de todos/as os/as atletas testados/as nos exames antidoping desde 0 ano de 2003 , com a data do teste, o nome do atleta, o local e o resultado do exame. Disponível em: http://www.cbat.org.br/anad/atletas_testados/atletas_quadro. asp?ano=2011. Acesso em :10 nov. 2012. 
Além disso, os testes, os exames e as investigações de controle do doping não se restringem mais aos momentos das competições. Na esteira dos princípios das sociedades de controle, a fiscalização antidoping estendeu-se aos treinos, às residências e a outros espaços da vida privada dos atletas. Mapear, registrar, interligar, constituir bancos de dados com o máximo de informações de atletas, suspeitos ou não, são algumas das ações previstas para o Programa Passaporte Biológico. Como observaram Moraes e Veiga-Neto (2008), nas sociedades de controle "[...] experimenta-se uma hiper-interatividade com os computadores e os bancos de dados." Assim, através das redes eletrônico-digitais, "informações digitalizadas são trocadas e distribuídas em volumes cada vez maiores, com total independência de lugares e cultura." (MORAES, VEIGA-NETO, 2008, p. 8).

A análise que fizemos da série de discursos, proveniente da WADA, referente ao Programa Passaporte Biológico do Atleta, mostrou-nos que, semelhante ao que estamos acompanhando em outros espaços institucionais, como é o caso, por exemplo, da Educação Escolar (MORAES, VEIGA-NETO, 2008), provavelmente também no campo do esporte de alto rendimento estejamos deixando para trás a sociedade disciplinar para adentrarmos as sociedades de controle, conforme apontou Gilles Deleuze (1992). Superação que o próprio Foucault sinalizava que deveria ocorrer, ao salientar que: "há cada vez mais categorias de pessoas que não estão submetidas à disciplina", o que evidencia "[...] que devemos nos separar, no futuro, da sociedade de disciplina de hoje", (FOUCAULT, 2006b, p. 268).

Todavia, de maneira similar ao que ocorria nas sociedades disciplinares, também nas sociedades de controle "[...] os governos controlam os cidadãos; e os cidadãos controlam a si mesmos" (COSTA, 2004, p.164). Assim, ações específicas, como é o caso do Passaporte Biológico do Atleta, o qual representa um efeito pontual das sociedades de controle no campo do esporte de alto rendimento, inserem-se na lógica da "governamentalidade" (FOUCAULT, 2006), uma forma de governar que se pauta por uma biopolítica transnacional, interessada no controle da vida e das populações. Na governamentalidade, a população aparece como interesse, finalidade e instrumento do governo,"[...] consciente diante do governo, do que ela quer, e inconsciente também, do que lhe fazem fazer (FOUCAULT, 2006a, p. 300) ${ }^{20}$.

\section{CONSIDERAÇÕES FINAIS}

A descoberta da estrutura do DNA, material que permite a transferência dos caracteres hereditários, na segunda metade do século XX, operou uma revolução na Biologia, que muda seu foco para a informação genética. Essa transformação, impulsionada pelas tecnologias da informação, permitiu descobrir o sequenciamento do genoma humano. A partir desse novo enfoque da Biologia, a compreensão sobre os seres humanos é novamente alterada. No discurso científico, o ser humano é identificado com as informações contidas no seu corpo, sejam elas biométricas ou genéticas.

Esses novos saberes contribuíram para que as ciências da vida ${ }^{21}$ alcançassem outro patamar após a descoberta do ADN em série, "em vez de 'gene', ente que se tornou cada vez mais vago, os biologistas falam agora de 'genoma', pelo qual compreendem o conjunto

20 Para maiores considerações sobre o conceito de governomentalidade consultar o artigo do próprio Michel Foucault: "A "Governomentalidade" (2006a) e as obras: (FOUCAULT, 2008a; 2008b).

21 Para uma síntese da historicidade das ciências da vida, a sua configuração e os seus movimentos de ruptura e reconfigurações, consultar PORTOCARRERO (2009). 
do material molecular contido nos pares de cromossomos de um organismo particular, e transmitido de geração em geração" (KECK; RABINOW, 2008, p. 86).

Frédéric Keck e Paul Rabinow destacam também que, em 2001, "[...] a fundação britânica Welcome Truste a empresa biotecnológica Celera Genomics anunciavam a realização do primeiro mapa completo do genoma humano" (KECK; RABINOW, 2008, p. 88). Essa nova realidade biotecnológica abriu as possibilidades de se criar novas formas de intervenções e de aplicação desses conhecimentos no esporte de alto rendimento, inclusive estendendo-os as novas práticas do doping/antidoping.

Com o advento de novas técnicas de doping genético ${ }^{22}$ e a introdução de DNA como substrato para os controles antidoping, presumimos que as técnicas de controle antidoping continuarão a mudar. As formas com que 0 doping, as modificações genéticas e outras intervenções médicas redefinem o caráter do corpo vêm forçando novas pesquisas e análises por parte da WADA. Entretanto, para que isso se materialize são necessários novos aportes financeiros. Nesse sentido, a WADA investe em torno de 5 milhões de euros por ano em pesquisas de testes antidoping para substâncias ainda indetectáveis (como por exemplo, 0 hormônio de crescimento humano - GH), um esforço para desenvolver métodos de detecção cada vez mais inovadores e aumentar a lista de substâncias proibidas. Além disso, mais de cinco milhões de euros são utilizados para estudos sobre doping genético.

Nesse artigo, especificamente, analisamos como os discursos, as estratégias e as políticas oficiais antidoping se interessam em controlar o universo do esporte de rendimento, vigiando e governando os corpos e as vidas dos atletas. Entretanto, nunca descartamos a possibilidade de que muitos atletas produzem formas de resistências, as quais conseguem burlar, desviar, escamotear e resistir aos interesses presentes nos programas, nos códigos e nas normas da WADA.

No campo da Educação Física brasileira, existe um número significativo de estudos que trata questões relacionadas ao biopoder, a biopolítica e a governamentalidade, como é o caso, entre outros, de Palma, et al. (2012); Rigo e Santolin, (2012); Fraga, (2006). Porém, a maioria desses estudos prioriza os temas do corpo e/ou da saúde. Também há alguns trabalhos, como o de Damico (2013), que trata da política pública de esporte e lazer para a juventude. No entanto, bem mais raros são os estudos que tratam do esporte de rendimento e das sociedades de controle. Nesse sentido, julgamos que seria pertinente para a área a realização de outras pesquisas dentro dessa perspectiva teórica, como, por exemplo, estudos que analisem as resistências às estratégias e políticas da WADA. Práticas esportivas discursivas e não discursivas que potencializam a vida (PELBART, 2003), que se opõem as estratégias de sujeição dos atletas e constituem linhas de fuga à lógica das sociedades de controle, especificamente em sua ação no campo esportivo.

\section{REFERÊNCIAS}

ARAÚJO, Hermetes. (Org.). Tecnociência e cultura: ensaios sobre o tempo presente. São Paulo: Estação Liberdade, 1998. 
CORRÊA, Adriana. 0 corpo digitalizado: bancos de dados genéticos e sua regulação jurídica. 2009. 275f. Tese (Doutorado) - Programa de Pós-Graduação em Direito, Setor de Ciências Jurídicas, Universidade Federal do Paraná, Curitiba, 2009.

COSTA, Rogério da. Sociedade de Controle. São Paulo em Perspectiva, São Paulo, v. 18, n. 1, p. 61-67, jan./mar. 2004.

DAMICO, José. Gestão da vida a partir do esporte e lazer em Grigny Centre-França.

Movimento, Porto Alegre, v. 19, n. 1, p. 11-31, jan./mar. 2013.

DELEUZE, Gilles. Conversações. Rio de Janeiro: Ed. 34, 1992a.

DELEUZE, Gilles. Foucault. São Paulo: Brasiliense, 1988.

DELEUZE, Gilles. Post-Scriptum sobre as Sociedades de Controle. In: DELEUZE, Gilles.

Conversações. Rio de Janeiro: Ed. 34, 1992b. p. 219-226.

FOUCAULT, Michel. A "governamentalidade". In: MOTTA, Manoel Barros da (Org.). Michel Foucault: estratégia, poder-saber. Rio de Janeiro: Forense Universitária, 2006a. p. 281-305.

FOUCAULT, Michel. A Sociedade Disciplinar em Crise. In: MOTTA, Manoel Barros da (Org.). Michel Foucault: estratégia, poder-saber. Rio de Janeiro: Forense Universitária, 2006b. p. 267 $-270$.

FOUCAULT, Michel. Nascimento da biopolítica. São Paulo: Martins Fontes, 2008a.

FOUCAULT, Michel. Segurança, território, população: 1977-1978. São Paulo: Martins Fontes, $2008 b$.

FRAGA, Alex Branco. Exercício da informação: governo dos corpos no mercado da vida ativa. Campinas, SP: Autores Associados, 2006.

HARAWAY, Donna. Manifesto ciborgue: ciência, tecnologia e feminismo socialista no final do século XX. In: SILVA, Tomaz Tadeu da (Org.). Antropologia do cyborg: as vertigens do póshumano. Belo Horizonte: Autêntica, 2000. p. 92-108.

KECK, Frédéric; RABINOW, Paul. Invenção e representação do corpo genético. In:

COURTINE, Jean-Jacques (org.). História do corpo: as mutações do olhar: o século XX. Petrópolis: Vozes, 2008. p. 83-105.

MORAES, Antônio Luiz; VEIGA-NETO, Alfredo. Disciplina e controle na escola: do aluno dócil ao aluno flexível. In: COLÓQUIO LUSO-BRASILEIRO SOBRE QUESTÕES CURRICULARES, 4., Florianópolis, 2008. Anais... p. 1-18.

PALMA, Alexandre et al. Os "pesos" de ser obeso: traços fascistas no ideário de saúde contemporâneo. Movimento, Porto Alegre, v. 18, n. 4, p. 99-119, out./dez. 2012.

PELBART, Peter Pál. Vida capital: ensaios de biopolítica. São Paulo: lluminuras, 2003.

PORTOCARRERO, Vera. As ciências da vida: de Canguilhem a Foucault. Rio de Janeiro: Editora Fiocruz, 2009.

RIGO, Luiz Carlos; SANTOLIN, C. Combate à obesidade: uma análise da legislação brasileira. Movimento, Porto Alegre, v. 18, n. 2, p. 279-296, abr./jun. 2012. 
Financiamento da CAPES na forma de uma bolsa de pós-doutorado (PNPD/CAPES) realizado na Escola Superior de Educação Física da Universidade Federal de Pelotas/UFPel. 